\title{
Asymmetry of the anterior skull base at the level of frontal ostium, a radioanatomical study*
}

\author{
Tomasz Gotlib, Magdalena Kuźmińska, Marta Held-Ziółkowska, \\ Kazimierz Niemczyk
}

Department of Otolaryngology, Medical University of Warsaw, Warsaw, Poland
Rhinology 52: 419-423, 2014

DOI:10.4193/Rhino14.071

*Received for publication:

March 14, 2014

Accepted: May 26, 2014

\begin{abstract}
Background: Radioanatomical studies have shown that the ethmoid roof is asymmetric in 10 to $40 \%$ of individuals. The right ethmoid roof has been found on average to be lower compared to the left. The aim of this study was to extend existing results by assessing asymmetry between the right and left anterior skull base at the level of the frontal ostium.
\end{abstract}

Methodology: Curved multiplanar reconstruction was used to analyse 247 consecutive paranasal sinus CT scans. The corresponding left and right parasagittal profiles of the skull base marked from the anterior ethmoidal artery to the level of the orbital roof were superimposed and compared.

Results: Asymmetry greater than $1 \mathrm{~mm}$ was found in $87 \%$ of patients, greater than $2 \mathrm{~mm}$ in $40.5 \%$ of patients, and greater than $3 \mathrm{~mm}$ in $8 \%$ of patients. The prevalence of the patients with lower skull base on the right side was greater than those with lower skull base on the left side at a ratio of more than 2:1.

Conclusion: Skull base asymmetry in the region of the frontal ostium is observed in a large percentage of the population and may be a potential source of complications during endoscopic sinus surgery.

Key words: frontal sinus, frontal ostium, skull base, anatomy, computerized tomography

\section{Introduction}

Endoscopic surgery of the frontal sinus is often challenging due to the narrow curved drainage pathway. Recognition and understanding of the anatomy of the frontal recess and frontal sinus ostium is essential for safe surgery of this region ${ }^{(1-4)}$. It was found that the anterior ethmoid roof is lower on average on the right side compared to the left side ${ }^{(4-7)}$. Little is known about the asymmetry of the anterior skull base at the level of the frontal sinus recess and frontal ostium. Current advances in CT imaging and development of software used for images reconstruction allow for detailed comparison between the curvature of right and left anterior skull base.

The aim of this study is to assess asymmetry between the right and left anterior skull base at the level of the frontal ostium.

\section{Patients and methods}

The study was approved by the University Ethics Committee. Overall, 948 CT examinations performed to assess sinonasal complaints were retrospectively assessed. Examinations acquired with slice thickness greater than $1 \mathrm{~mm}$, with a nonregular slice interval, gantry tilt, or performed using cone beam CT were eliminated.

CT images were analyzed with multiplanar reconstructions (MPR) in the bony window (window level - 300 ; window width -1500). The patients with unilateral or bilateral frontal sinus agenesis or hypoplasia, after osteoplastic flap procedure, Draf IIb or III procedures, with frontal bone fractures, and those with neoplastic or expansile lesions of the frontal recess and sinus were excluded. The remaining 247 examinations of adult Cauca- 
sians ( 126 females and 121 males) mean age 43 years $(S D=16$, range 18-82 years) were evaluated further.

Examinations were evaluated using Osirix (Apple, CA, USA) software. The coronal, sagittal and horizontal planes were set using lateral aspect of orbits, the floor of the nasal cavity and crista galli. The profile of the skull base was marked from the anterior ethmoidal artery entry point up to the level of the orbital roof in the parasagittal plane crossing the midpoint between the lamina papyracea and lateral lamella of the cribriform plate. For the purpose of establishing the orbital roof level, the horizontal plane parallel to the floor of the nasal cavity was used. The profile of the right skull-base was superimposed over the corresponding profile of the left skull base using 3D curved MPR (Figure 1). Examinations were cross-checked by marking the left skull base and superimposing its profile over the right side. The maximum distance between the right and left contours of the skull base was noted for each subject (Figure 1). Two observers blinded to each other's findings evaluated each CT examination.

\section{Statistical analyses}

Interobserver agreement was analyzed using kappa statistics. The differences in the prevalence of skull base configurations were analyzed using Cochran's Q test.

\section{Results}

Three types of skull-base profile configurations were observed:

1. The profiles are positioned one above the other (Figures 1 , 2).

2. The superimposed profiles cross, changing position with respect to each other from below to above or from above to below (Figure 3).

3. The profiles overlap.

Asymmetry greater than $1 \mathrm{~mm}$ between the sides was observed in 215 (87\%) subjects, greater than $2 \mathrm{~mm}$ in 101 (40.8\%), and greater than $3 \mathrm{~mm}$ in 20 (8\%) patients. The interobserver agreement $(\mathrm{K})$ was $95 \%$. The results are summarized in Table 1.
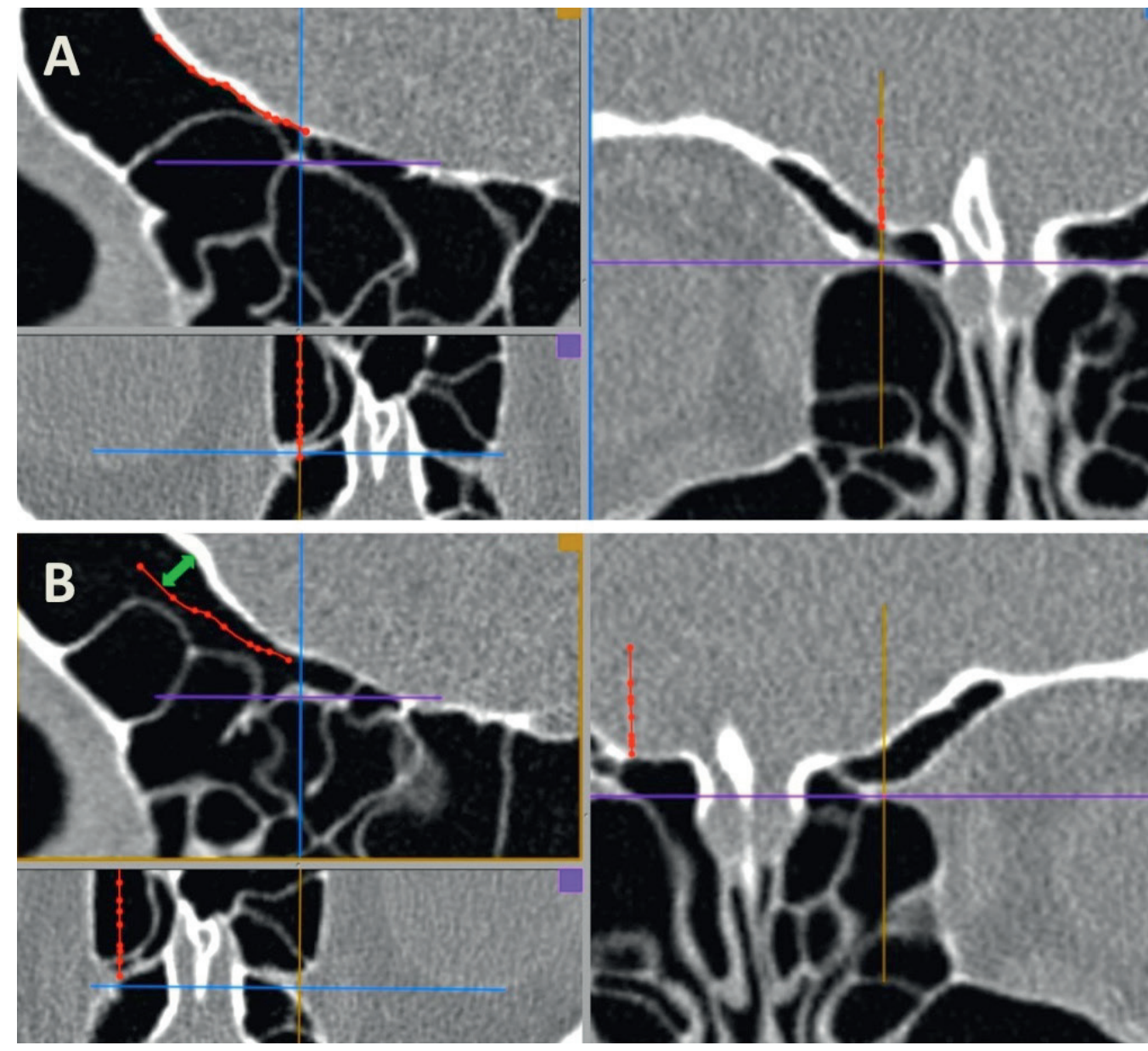

Figure 1. Measuring the distance between the right and left skull base contour using multiplanar CT reconstruction.

A - The right anterior ethmoidal artery is identified in three planes (shown by the intersection of reference lines). The anterior skull base is marked in parasagittal plane crossing half way between the lamina papyracea and lateral lamella of the cribriform plate from the level of the right anterior ethmoidal artery. B -The marked right skull-base segment (dotted red line visible in three planes) is superimposed over the corresponding left parasagittal profile. The maximum distance between the two profiles is measured (green arrow). 


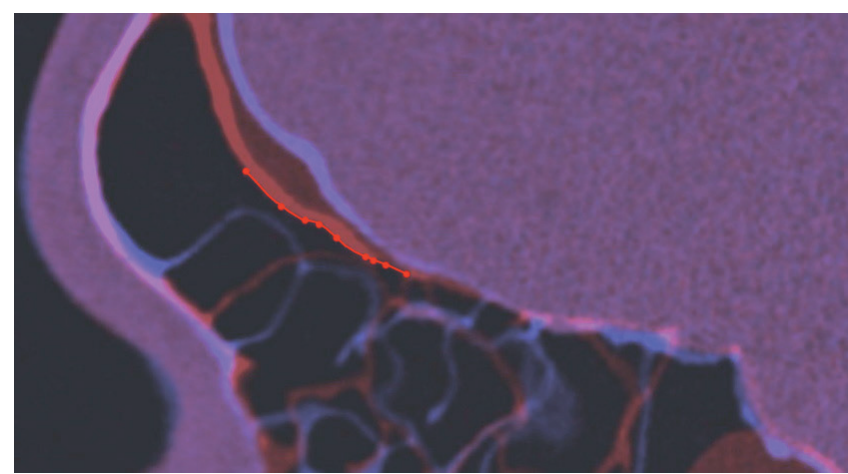

Figure 2. Superimposed corresponding right and left parasagittal sinus CT sections (coloured in red and blue, respectively). The evaluated segment of the skull base is marked with a red dotted line on the right side.

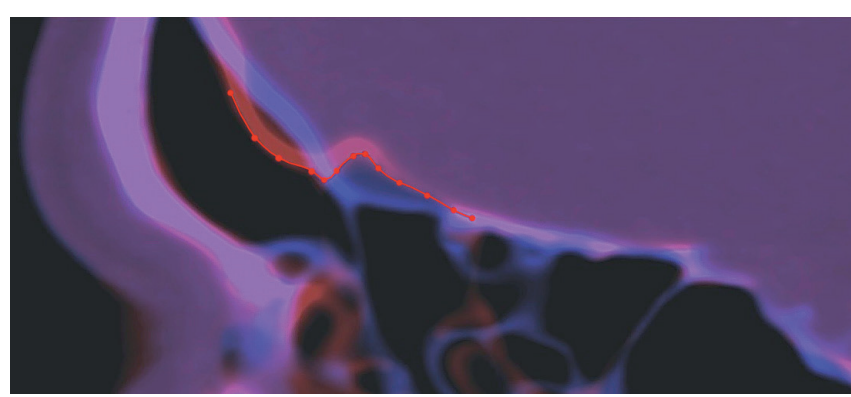

Figure 3. Superimposed corresponding right and left parasagittal sinus $\mathrm{CT}$ sections (coloured in red and blue, respectively). The evaluated segment of the skull base is marked with a red dotted line on the right side.

\section{Discussion}

Multiplanar reconstruction (MPR) of CT images gives the possibility to assess the architecture of the ethmoid labyrinth, and is a valuable tool for planning the surgery ${ }^{(2,8)}$.

Several studies focused on asymmetry of the ethmoid roof posterior to the anterior ethmoidal artery and compared the position of left and right olfactory groove or fovea ethmoidalis $(5-7,9,10)$. Jones at al. did not find any differences in the height of the ethmoid roof in 151 patients ${ }^{(10)}$. Other authors reported asymmetry of the ethmoid roof in about 10 to $40 \%$ of subjects, which is less compared to the asymmetry of the skull base at the level of the frontal ostium found in our study ${ }^{(6,7,9)}$. In all of these studies the majority of asymmetric ethmoid roofs were lower on the right side. Analysis of consecutive $100 \mathrm{CT}$ examinations performed by Zacharek et al. showed that there is no difference in the height of the ethmoid roof between the right and left sides in the region of the sphenoethmoid junction. In contrast, in the region of the anterior ethmoidal artery, the mean height of the right ethmoid roof was smaller compared to the left ${ }^{(5)}$. The frontal sinus is often variable in shape and size, asymmetric, occasionally absent on one or both sides, which is not that common in other paranasal sinuses ${ }^{(11)}$. This variability is very likely to be associated with the asymmetry of the skull base in
Table 1. Percentage of skull base asymmetry configurations.

\begin{tabular}{|cccc|}
$\begin{array}{c}\text { Type of } \\
\text { configuration }\end{array}$ & $\begin{array}{c}\text { Difference } \\
>1 \mathbf{~ m m}\end{array}$ & $\begin{array}{c}\text { Difference } \\
>\mathbf{2} \mathbf{~ m m}\end{array}$ & $\begin{array}{c}\text { Difference } \\
>\mathbf{3 ~ m m}\end{array}$ \\
\hline Right lower & $118(48 \%)^{*}$ & $67(27 \%)^{*}$ & $14(5.5 \%)^{*}$ \\
\hline Left lower & $56(22.5 \%)$ & $25(10 \%)$ & $5(2 \%)$ \\
\hline Cross ${ }^{\#}$ & $41(16.5 \%)$ & $9(3.5 \%)$ & $1(0.4 \%)$ \\
\hline $\begin{array}{c}\text { Total (right, left, } \\
\text { cross) }\end{array}$ & $215(87 \%)$ & $101(40.5 \%)$ & $20(8 \%)$ \\
\hline $\begin{array}{c}\text { Equal / } \\
\text { no difference }\end{array}$ & $32(13 \%)$ & $146(59.5 \%)$ & $227(92 \%)$ \\
\hline
\end{tabular}

\# Cross - Superimposed profiles of the left and right skull-based crossed * The difference between "right lower" and "left lower" was statistically significant $(p<0.05)$.

the sagittal profile at the level of the frontal ostium. These data, together with the results of our study, suggest that the skull base of the anterior cranial fossa is symmetric in the posterior ethmoid region, tends to be asymmetric in the anterior ethmoid region, and becomes the most asymmetric in the region of the frontal ostium.

The studies on paranasal sinuses development using CT revealed that the left frontal sinuses reached bigger sizes compared to the right ${ }^{(11,12)}$. The authors did not find an explanation for this phenomenon. Unilateral frontal sinus aplasia, which can be related to anterior skull base asymmetry, was reported more frequently on the right side compared to the left in most of the studies ${ }^{(13-15)}$.

A possible explanation of the above mentioned asymmetry is that lateralization of the brain influences skull-base development. The term "brain lateralization" can refer to both handedness, and to asymmetric language and also visuospacial functions of the hemispheres. Handedness and language specialization are not perfectly correlated ${ }^{(16)}$.

Kizilkaya et al. studied asymmetry of the olfactory groove in relation to handedness. The authors found that in a majority of cases the olfactory groove was lower on the right side in righthanded persons, on the left side in left-handers, and was equal in ambidextrous subjects ${ }^{(9)}$.

It is generally accepted that there is left hemispheric brain specialization for language abilities and right hemispheric specialization for visuospacial performance in most humans. This specialization results in macroscopic brain asymmetry known as Yakovlevian torque, which is the tendency of the brain to twist along the longitudinal axis with protrusion of the right frontal and left occipital poles beyond the corresponding left and right edges ${ }^{(17)}$. This brain asymmetry is reflected in the shape of the 
inner skull surface as shown with the use of 3D MRI reconstruction ${ }^{(18)}$.

Brain asymmetry is observed as early as in the fetal and newborn periods. However, left hemispheric brain specialization for language abilities was found to develop in early childhood during speech development at the time when the frontal sinus is yet not developed. In contrast, visuospacial performance related to the right hemisphere develops gradually between the ages of 6 and 16, thus simultaneously with the development of the frontal sinuses ${ }^{(19)}$.

Although relatively small, the described differences in the level of the anterior skull base between right and left sides may affect the possibility to inspect the frontal sinus with an endoscope during sinus surgery, or even access it with surgical tools, as the frontal ostium is narrow and angulated. These differences may also influence surgical complication rates. Intracranial penetration during endoscopic sinus surgery was found to occur more frequently on the right side ${ }^{(20)}$. It was hypothesized that this can be due to poorer visualization of the right ethmoid cavity for the right-handed surgeon, and due to asymmetry of the ethmoid roof. The described asymmetry of the skull base at the level of the frontal ostium, which is more frequent on the right side, may be an additional factor.

Another potential consequence of the described asymmetry to be considered is its impact on rhinosinusitis. It can be hypothesized that ventilation and drainage of the frontal sinus can be impaired on the side with a lower skull-base. Anatomical variations such as concha bullosa, Haller's cell or septal deviation are known factors predisposing to recurrent acute sinusitis ${ }^{(21,22)}$. In chronic rhinosinusitis the contribution of these variations is questioned ${ }^{(22,23)}$; however, there are still not enough data on the role of a single type of variants. The frontal sinus drainage pathway is relatively long and dependent on several anatomical structures such as agger nasi cells, bulla lamella, frontal cells type I-IV, supraorbital ethmoid cell or frontal intersinus septal cell. Thus, it could be difficult to establish the role of single ananomical factor predisposing to acute or chronic frontal sinusitis. On the other hand, orbital complications of frontal sinusitis were observed more frequently on the left side, more commonly in males compared to females ${ }^{(24)}$. This may be related to the greater size of the frontal sinus on the left side in children and adults, the greater width and length of the frontal sinuses in males, together with more frequent aplasia of the frontal sinus in females compared to males ${ }^{(11)}$. Greater pneumatization is associated with the bigger area of the mucoperiostium covering the orbital wall, which potentially increases the risk of orbital complications.

\section{Conclusion}

Skull base asymmetry in the region of the frontal ostium is observed in a large percentage of the population and may be a potential source of complications during endoscopic sinus surgery.

\section{Authorship contribution}

TG: Research concept and design, collection and analysis of data, writing of the article; MK: data analysis; MHZ: data analysis; $\mathrm{KN}$ : critical revision of the article

\section{Conflicts of Interest}

The authors have no funding, financial relationships, or conflicts of interest to disclose.

\section{References}

1. Wormald PJ. Three-dimensional building block approach to understanding the anatomy of the frontal recess and frontal sinus. Oper Tech Otolaryngol Head Neck Surg. 2006; 17: 2-5.

2. Leunig A, Sommer B, Betz CS, Sommer F. Surgical anatomy of the frontal recess - is there a benefit in multiplanar CT-reconstruction. Rhinology. 2008; 46: 188194.

3. Lee WT, Kuhn FA, Citardi MJ. 3D computed tomographic analysis of frontal recess anatomy in patients without frontal sinusitis. Otolaryngol Head Neck Surg. 2004; 131: 164-173.

4. Lund VJ, Stammberger $H$, Fokkens WJ, Beale T, Bernal-Sprekelsen M, Eloy P. et al. European position paper on the anatomical terminology of the internal nose and paranasal sinuses. Rhinology 2014; suppl 24: 1-34.
5. Zacharek MA, Han JK, Allen R, Weissman JL, Hwang PH. Sagittal and coronal dimensions of the ethmoid roof: A radioanatomic study. Am J Rhinol. 2005; 19(4): 348-352.

6. Lebowitz RA, Terk A, Jacobs JB, Holliday RA Asymmetry of the ethmoid roof:Analysis using coronal computed tomography. Laryngoscope. 2001; 111: 2122-2124.

7. Dessi P, Moulin G, Triglia JM et al. Differences in height of the left and right ethmoid roofs: A possible risk factor for ethmoidal surgery. Prospective study of 150 scans. J Laryngol Otol. 1994; 108: 261-262.

8. Han D, Zhang L, Ge W, Tao J, Xian J, Zhou B. Multiplanar computed tomographic analysis of the frontal recess region in Chinese subjects without frontal sinus disease symptoms. ORL. 2008; 70: 104-112.

9. Kizilkaya E, Kantarci M, Basekim CC. Asymmetry of the height of the ethmoid roof in relationship to handedness. Laterality. 2006; 11: 297-303.
10. Jones TM, Almahdi JMD, Bhalla RK et al. The radiological anatomy of the anterior skull base. Clin Otolaryngol. 2002; 27: 101-105.

11. Spaeth J, Krügelstein U, Schlöndorff G. The paranasal sinuses in CT-imaging: development from birth to age 25. Int J Pediatr Otorhinolaryngol. 1997; 39: 25-40.

12. Wolf G, Anderhuber W, Kuhn F. Development of the paranasal sinuses in children: Implications for paranasal sinus surgery. Ann Otol Rhinol Laryngol. 1993; 102: 705-711.

13. Nowak R, Mehls G. Die aplasien der sinus maxillares und frontales unter besenderer Berucksichtigung der pneumatisation bei spalttragern. Anat Anz. 1977; 142: 441-450.

14. Yoshino M, Miyasaka S, Sato H,Seta S. Classification system of frontal sinus patterns by radiography. Its application to identification of unknown skeletal remains. Forensic Sci Int. 1987; 34: 289-99.

15. Cakur B, Sumbullu MA, Durna NB. Aplasia 
and agenesis of the frontal sinus in Turkish individuals: A retrospective study using dental volumetric tomography. Int J Med Sci. 2011; 8: 278-282

16. Toga WA, Thompson. PM Mapping brain asymmetry. Nature Rev Neurosci. 2003; 4: 37-48.

17. Yakovlev PI. Morphological criteria of growth and maturation of the nervous system in man. Res Publ Assoc Res Nerv Ment Dis. 1962; 39: 3-46.

18. Fourier M, Combes B, Braga J, Roberts N, Prima S. Mapping the distance between the brain and the inner surface of the skull: interest for the study of fossil endocasts. Am J Phys Anthropol. 2011; 144: 137-138.

19. Hugdahl K. Hemispheric asymmetry: Contributions from brain imaging. Wiley Interdisciplinary Reviews: Cognitive
Science $2011 ; 2: 461-478$.

20. Dessi P, Castro F, Triglia JM et al. Major complications of sinus surgery: A review of 1192 procedures. J Laryngol Otol. 1994 108: 212-215.

21. Alkire BC, Bhattacharyya N. An assessment of sinonasal anatomic variants potentially associated with recurrent acute rhinosinusitis. Laryngoscope. 2010; 120: 631-634.

22. Fokkens WJ, Lund VJ, Mullol J, Bachert C, et al. European position paper on rhinosinusitis and nasal polyps 2012. Rhinology. 2012; suppl. 23: 4-305.

23. Bolger WE, Butzin CA, Parsons DS. Paranasal sinus bony anatomic variations and mucosal abnormalities: CT analysis for endoscopic sinus surgery. Laryngoscope. 1991; 101: 56-64.

24. Adelson RT, Marple BF. Orbital complica- tions of frontal sinusitis. In: Kountakis $S$, Senior B, Draf W, eds. The frontal sinus, Heidelberg, Berlin, New York: SpringerVerlag; 2005: 59-66.

\section{Tomasz Gotlib MD PhD}

Department of Otolaryngology

Medical University of Warsaw, ul.

\section{Banacha $1 \mathrm{a}$}

02-097, Warsaw

Poland

Tel: +48-22-599 2509

E-mail: tgotlib@wum.edu.pl 